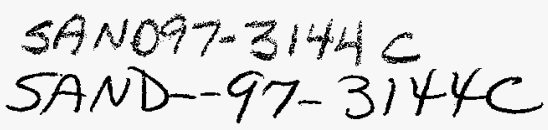

\title{
STRUCTURE-PROPERTY RELATIONSHIPS OF BaCeO PEROVSKITES FOR THE OXIDATIVE DEHYDROGENATION OF ALKANES
}

\author{
T. M. Nenoff, N. B. Jackson, J. E. Miller, A. G. Sault, D. Trudell
}

Sandia National Laboratories, Catalysis and Chemical Technologies Department, PO Box 5800, Albuquerque, NM 87185-0710

$$
\text { CONF }
$$

\section{ABSTRACT}

The oxidative dehydrogenation (ODH) reactions for the formation of two important organic feedstocks ethylene and propylene are of great interest because of the potential in capital and energy savings associated with these reactions. Theoretically, $\mathrm{ODH}$ can achieve high conversions of the starting materials (ethane and propane) at lower temperatures than conventional dehydrogenation reactions. The important focus in our study of ODH catalysts is the development of a structure-property relationship for catalyst with respect to selectivity, so as to avoid the more thermodynamically favorable combustion reaction. Catalysts for the ODH reaction generally consist of mixed metal oxides. Since for the most selective catalyst lattice oxygen is known to participate in the reaction, catalysts are sought with surface oxygen atoms that are labile enough to perform dehydrogenation, but not so plentiful or weakly bound as to promote complete combustion. Also, catalysts must be able to replenish surface oxygen by transport from the bulk.

Perovskite materials are candidates to fulfill these requirements. We are studying $\mathrm{BaCeO}_{3}$ perovskites doped with elements such as $\mathrm{Ca}, \mathrm{Mg}$, and $\mathrm{Sr}$. During the $\mathrm{ODH}$ of the alkanes at high temperatures, the perovskite structure is not retained and a mixture of carbonates and oxides is formed, as revealed by XRD. While the Ca doped materials showed enhanced total combustion activity below $600^{\circ} \mathrm{C}$, they only showed enhanced alkene production at $700^{\circ} \mathrm{C}$. Bulk structural and surface changes, as monitored by powder X-ray diffraction, and X-ray photoelectron spectroscopy are being correlated with activity in order to understand the factors affecting catalyst performance, and to modify catalyst formulations to improve conversion and selectivity.

\section{INTRODUCTION}

Ethylene and propylene are now the two most important organic feedstocks manufactured by U.S. industry.' These chemicals are currently manufactured by steam cracking of natural gas liquids, an extremely energy intensive, nonselective process. The development of catalytic technologies, such as selective oxidative dehydrogenation, with the potential for greater selectivity and lower energy consumption than steam cracking, can have a profound effect on the competitiveness of the U.S. chemical industry, and prevent the movement of these key energy industries to offshore sites.

A generic equation describing the oxidative dehydrogenation $(\mathrm{ODH})$ reaction is $\mathrm{C}_{\mathrm{n}} \mathrm{H}_{2 \mathrm{n}+2}+\mathrm{O}_{2} \rightarrow \mathrm{C}_{\mathrm{n}} \mathrm{H}_{2 \mathrm{n}}+\mathrm{H}_{2} \mathrm{O}$. Because this is an exothermic reaction, the potential exists for low temperature operations compared to straight dehydrogenation methods which are endothermic and challenged by equilibrium constraints. However, the $\mathrm{ODH}$ reaction also

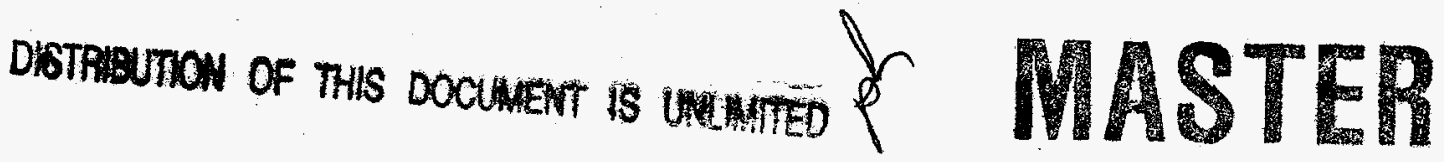




\section{DISCLAIMER}

This report was prepared as an account of work sponsored by an agency of the United States Government. Neither the United States Government nor any agency thereof, nor any of their employees, makes any warranty, express or implied, or assumes any legal liability or responsibility for the accuracy, completeness, or usefulness of any information, apparatus, product, or process disclosed, or represents that its use would not infringe privately owned rights. Reference herein to any specific commercial product, process, or service by trade name, trademark, manufacturer, or otherwise does not necessarily constitute or imply its endorsement, recommendation, or favoring by the United States Government or any agency thereof. The views and opinions of authors expressed herein do not necessarily state or reflect those of the United States Government or any agency thereof. 


\section{DISCLAMIXR}

Portions of this docoment moly be illegibie in electronic image products. Images are produced from the best availabie origion docementert 
favors complete oxidation of the alkane. To combat this thermodynamic trend, a catalyst needs to have good selectivity. For selective catalysts the reaction usually involves the lattice oxygen of the material, as shown in the following general formulas: $(\mathrm{L}=$ lattice, $\mathrm{V}=$ vacancies) (1) $\mathrm{C}_{n} \mathrm{H}_{2 n}+\mathrm{O}_{\mathrm{L}} \rightarrow \mathrm{C}_{n} \mathrm{H}_{2 n+1}+\mathrm{OH}$; (2) $\mathrm{C}_{n} \mathrm{H}_{2 n+1}+\mathrm{OH} \rightarrow \mathrm{C}_{n} \mathrm{H}_{2 n}+\mathrm{H}_{2} \mathrm{O}+\mathrm{O}_{V}$; (3) $\mathrm{O}_{2}+2 \mathrm{O}_{\mathrm{V}} \rightarrow 2 \mathrm{O}_{\mathrm{L}}$

According to Mars-van Krevelen mechanism², oxygen does not necessarily readsorb at lattice vacancies. The active catalytic site of the metal oxide is reduced as the alkane is oxidized. This site is then reoxidized by oxygen from a second site in the metal oxide lattice, usually associated with a different type of metal atom. The second site is then reoxidized by oxygen (introduced from the gas phase) and transported through the lattice.

Literature has shown that rare earth metal oxides are of considerable interest for the oxidatived dehydrogenation of alkanes. ${ }^{3}$ As early as $1978, \mathrm{Mo} / \mathrm{V} / \mathrm{Nb} / \mathrm{O}$ systems ${ }^{4}$ have been reported to be very active for ethane oxidative dehydrogenation. However, the catalytically active site is still not well characterized. Perovskites containing rare earth metal oxides possess the unique capability of sustaining nonstoichiometric compositions without affecting their structural integrity. Oxygen-deficient perovskites exhibit ionic conductivity and catalytic activity due to the facile loss and gain of oxygen. ${ }^{5-11}$ Oxygen vacancies can be introduced into a rare earth containing perovskite, such as $\mathrm{BaCeO}_{3}$, by doping in metal oxides, so that the new phase exhibits mixed conduction of mobile oxygen ion and electron hole. ${ }^{11-13}$ This mobility led researchers to studies which show $\mathrm{SrCe}_{1-\mathrm{x}} \mathrm{Yb}_{\mathrm{x}} \mathrm{O}_{3-\mathrm{x}}(\mathrm{x}=0-0.5)$ as an active catalyst with respect to oxidative dehydrogenation of ethane. ${ }^{14}$ Over $400^{\circ} \mathrm{C}, \mathrm{La}_{1-x} \mathrm{Sr}_{\mathrm{x}} \mathrm{FeO}_{3-\delta}$ is another good perovskite-like ODH catalysts for ethane. ${ }^{15}$.

We have chosen to investigate crystalline perovskite-like catalysts with the general formulas $\mathrm{BaCeO}_{3-\alpha}, \mathrm{BaM}_{\mathrm{x}} \mathrm{Ce}_{1-\mathrm{x}} \mathrm{O}_{3-\alpha}$, and $\mathrm{Ba}_{1-\mathrm{x}} \mathrm{M}_{\mathrm{x}} \mathrm{CeO}_{3-\alpha}$. Perovskites can be formed from reducible oxides, which are required to provide lattice oxygen. Furthermore, they allow for a wide range of stoichiometric substitutions without loss of crystallographic structure, which is easily monitored. These catalysts are being extensively characterized by powder X-ray diffraction (XRD), and X-ray Photoelectron Spectroscopy (XPS) and were tested for catalytic activity (as monitored by gas chromatography (GC)) with respect to the oxidative dehydrogenation of ethane to ethylene.

\section{EXPERIMENT}

\section{Catalyst Preparation:}

Our catalysts were the following target perovskite-like compounds: $\mathrm{BaCeO}_{3-\alpha}$, $\mathrm{BaM}_{\mathrm{x}} \mathrm{Ce}_{1-\mathrm{x}} \mathrm{O}_{3-\alpha}, \mathrm{Ba}_{1-\mathrm{x}} \mathrm{M}_{\mathrm{x}} \mathrm{CeO}_{1-\alpha}$, with $\mathrm{x}=0.2$. The starting materials (all from Sigma Chemicals) were $\mathrm{Ba}\left(\mathrm{CO}_{3}\right)_{2}(99.999 \%), \mathrm{CeO}_{2}(99.999 \%)$ and dopant metals $\left(\mathrm{La}_{2} \mathrm{O}_{3}\right.$, $99.999 \% ; \mathrm{Y}_{2} \mathrm{O}_{3}, 99.999 \% ; \mathrm{Nb}_{2} \mathrm{O}_{3}, 99.999 \% ; \mathrm{MgO}, 99.99 \% ; \mathrm{Ca}\left(\mathrm{CO}_{3}\right)_{2}, 99.999 \%$; $\left.\mathrm{Sr}\left(\mathrm{CO}_{3}\right)_{2}, 99.995 \%\right)$. They were mixed for three hours in an agate ball mill. Each mixture was heated $\left(300^{\circ} \mathrm{C} /\right.$ hour ramp rate) in air at $1250^{\circ} \mathrm{C}$ for 5 hours in platinum crucibles. Each sample was milled, and then refired in the crucibles under the previous conditions. 
Note that alkaline earth samples were pressed into pellets (40-60+ mesh size) before final firing and retained their pellet forms. All starting materials and catalyst products were stored under inert atmosphere $\left(\mathrm{N}_{2}\right)$ until needed for reactions or testing.

\section{Bulk Catalyst Characterization:}

Powder X-ray diffraction data were collected at room-temperature on a Siemens Model D500 automated diffractometer, with $\Theta-2 \Theta$ sample geometry and $\mathrm{Cu} \mathrm{K}_{\alpha}$ radiation, between $2 \Theta=5$ and $60^{\circ}$, step size $0.05^{\circ}$.

\section{ODH Catalyst Testing:}

The catalysts were tested for ODH of ethane in a stainless steel flow system. Samples were tested either in powder or pellet form (40-60+ mesh) by flowing $83 \mathrm{sccm}$ of a $10.5 \% \mathrm{O}_{2}$ in $\mathrm{N}_{2}$ mixture and $17 \mathrm{sccm} \mathrm{C}_{2} \mathrm{H}_{6}$ over $0.250 \mathrm{~g}$ of material in a $4.9 \mathrm{~mm}$ I.D. stainless steel tube. The reaction temperatures, measured with a thermocouple positioned inside the reactor tube just above the catalyst, ranged from 350 to $750^{\circ} \mathrm{C}$. Reactants and products were analyzed with an on-line MTI GC utilizing a $10 \mathrm{~m}$ molecular sieve $5 \mathrm{~A}$ PLOT column $\left(\mathrm{O}_{2}, \mathrm{CH}_{4}, \mathrm{CO}\right)$ and a $8 \mathrm{~m}$ Poraplot $\mathrm{Q}$ column $\left(\mathrm{CO}_{2}, \mathrm{C}_{2} \mathrm{H}_{4}, \mathrm{C}_{2} \mathrm{H}_{6}\right)$. No additional products other than water were detected. Tests conducted in an empty reactor tube indicated that the thermal contribution to the reaction was negligible below $550^{\circ} \mathrm{C}$, increasing to $2 \%$ propane conversion at $600{ }^{\circ} \mathrm{C}, 5 \%$ at $650^{\circ} \mathrm{C}, 30 \%$ at $700{ }^{\circ} \mathrm{C}$, and $40 \%$ at $750^{\circ} \mathrm{C}$.

\section{Catalyst Surface Characterization:}

X-ray Photoelectron Spectroscopy (XPS) measurements were made in a combined ultra-high vacuum (UHV) surface analysis/atmospheric pressure reactor system ${ }^{16,17}$ that allows measurement of the surface properties of catalytic materials before and after exposure to reactive environments without intervening exposure to air. With this system, various perovskite catalysts were analyzed following treatment in reactive environments to simulate reaction conditions. The treatments were designed to simulate increasing conversion of ethane and consumption of oxygen with increasing reaction temperature. Thus, the conditions studied included treatment in a stoichiometric mixture of 108 Torr ethane and 54 Torr oxygen at $500^{\circ} \mathrm{C}$ for $1 \mathrm{~h}$, treatment in lean mixture of 108 Torr ethane and 10 Torr oxygen at $600^{\circ} \mathrm{C}$ for $1 \mathrm{~h}$, treatment in 108 Torr ethane at $700^{\circ} \mathrm{C}$ for $1 \mathrm{~h}$, and treatment in 108 Torr ethane plus 54 Torr $\mathrm{CO}_{2}$ at $700^{\circ} \mathrm{C}$ for $1 \mathrm{~h}$. Prior to all treatments the samples were outgassed in vacuum for five minutes at the desired reaction temperature to remove any volatile organic species. XP spectra were taken following each treatment using a non-monochromatic $\mathrm{Mg} \mathrm{K} \alpha$ source with an analyzer resolution of $1.0 \mathrm{eV}$. Because of the insulating nature of the perovskites, some sample charging always occurred and binding energies were referenced to the $\mathrm{Ba} 3 \mathrm{~d}_{5 / 2}$ peak at $779.7 \mathrm{eV} .^{18,19}$ Spectra were collected in the $\mathrm{Ba} 3 \mathrm{~d}, \mathrm{Ce} 3 \mathrm{~d}, \mathrm{O} 1 \mathrm{~s}$, and $\mathrm{C} 1 \mathrm{~s}$ regions for each sample, as well as the $\mathrm{Ca} 2 \mathrm{p}$ or $\mathrm{Mg} 2 \mathrm{p}$ regions for samples containing these modifiers. All peaks 
were subjected to Tougaard background subtraction followed by integration of peak areas to determine relative XPS signal intensities.

\section{RESULTS and DISCUSSION}

Our motivation for studying metal oxide perovskite-like materials as oxidative dehydrogenation catalysts is two-fold. First, as described above, we hope to enhance utilization of alkanes as precursors to the commodity chemicals (propylene and ethylene) commonly used in industry. Second, we would like to study the factors affecting catalyst performance, such as activity and selectivity. An end result would be the understanding of structure-property relationships of the catalysts, and a predictive capability in choice of catalyst per specific reaction.

Catalyst Testing: $\mathrm{BaCeO}_{3}$ and $\mathrm{BaCe}_{1-\mathrm{x}} \mathrm{M}_{\mathrm{x}} \mathrm{O}_{3-\alpha}(\mathrm{M}=\mathrm{Ca}, \mathrm{La}, \mathrm{Y}, \mathrm{Nd} ; \mathrm{x}=0.05,0.10,0.15$, 0.20 ) phases were tested for the ODH of ethane in the powder form. Each of these materials showed enhanced activity for propane conversion when compared to the thermal reaction at temperatures less than $650^{\circ} \mathrm{C}$. However, $\mathrm{CO}_{2}$ was the favored product and the ethylene yield was never significantly improved over that of the thermal reaction. At $700^{\circ} \mathrm{C}$, many of the materials, most notably the Ca doped materials showed enhanced conversion of ethane to ethylene. For example the $\mathrm{Ca} 0.10$ material showed a $34 \%$ yield (ethylene produced / ethane fed) of ethylene compared to a $17 \%$ yield for the thermal runs. For catalysts that exhibit enhanced ethylene yield, the selectivity to ethylene shows sharp increases in the temperature range of $650-700^{\circ} \mathrm{C}$ (see figure 1).

$\mathrm{XRD}$ analysis of catalysts recovered from the reactor show that the perovskites have significantly degraded, and that new phases have formed. These observations suggest that at temperatures greater than $650^{\circ} \mathrm{C}$, the ethylene yield was enhanced either through the destruction of a combustion enhancing perovskite phase, through the formation of new more selective phase, or a combination of both. In contrast to this result, cycling the reactor to $750^{\circ} \mathrm{C}$ changed the selectivity over the material at lower temperatures. For example, in one experiment the ethylene yield for the $\mathrm{Ca} 0.10$ material at $700^{\circ} \mathrm{C}$ was reduced by more than half by cycling the reactor to $750^{\circ} \mathrm{C}$. This suggests that the perovskite, or at least an intermediate, phase may be the more selective phase at elevated temperatures.

Drawing on these results several new catalysts were produced. These new materials were based on the $\mathrm{BaCeO}_{3}$ baseline material but were doped with Group II elements $(\mathrm{Mg}, \mathrm{Ca}$, and $\mathrm{Sr})$. Since oxygen vacancies may have led to combustion reactions, the precursors were mixed in ratios intended to result in dopant substitution on the divalent $\mathrm{Ba}$ site. In addition, to remove pressure drop effects, the materials were pelletized. The materials from this family tested for catalytic activity to date include $\mathrm{Ba}_{0.8} \mathrm{M}_{0.2} \mathrm{CeO}_{3-\alpha}(\mathrm{M}=\mathrm{Mg}, \mathrm{Ca}, \mathrm{Sr})$ and $\mathrm{BaCe}_{0.8} \mathrm{Ca}_{0.2} \mathrm{O}_{3-\alpha}$. None of these materials, including $\mathrm{BaCe}_{0.8} \mathrm{Ca}_{0.2} \mathrm{O}_{3-\alpha}$ which had performed fairly well in the powder form, yielded as much ethylene as the thermal (non-catalytic) run at $700^{\circ} \mathrm{C}$. In part this was probably 
due to a decrease in catalytic surface area. An interesting phenomenon was noted when the activity was monitored over several hours time. The yield (and selectivity) of ethylene just after the reactor had stabilized at $700^{\circ} \mathrm{C}$ was consistently much higher than that fifteen minutes into the reaction (see figure 2). This then reached a minimum value before gradually recovering some, but not all of its selectivity (and hence yield) with a leveling occurring several hours into the reaction.

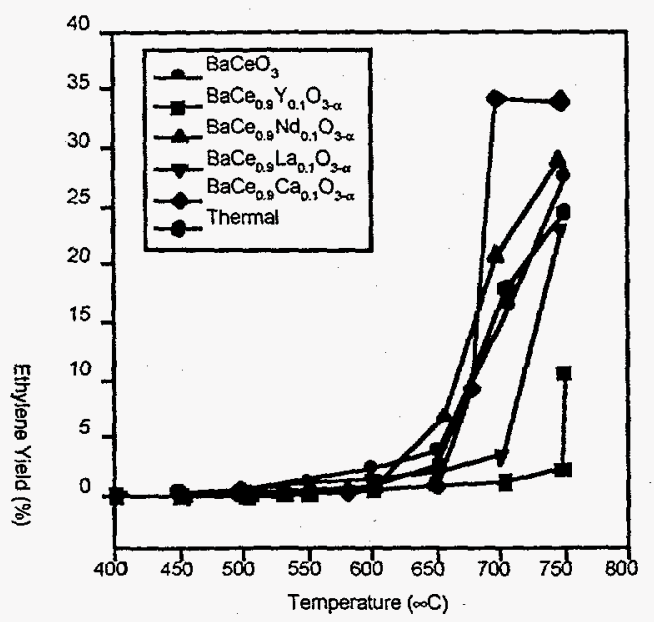

Figure 1: Ethylene yield as a function of temperature for perovskite powders.

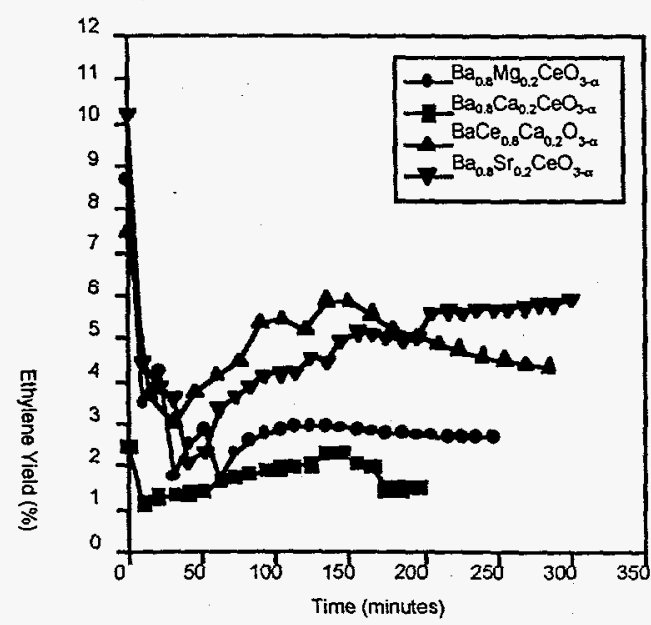

Figure 2: Ethylene yield at $700^{\circ} \mathrm{C}$ for perovskite granules.

XRD: The perovskite-like doped barium cerium oxide phases had a moderate hardness and were very dense (pellets were pressed for ease of gas flow during catalytic reactions). The XRD of the pure $\mathrm{BaCeO}_{3}$ and the $\mathrm{BaM}_{\mathrm{x}} \mathrm{Ce}_{1-\mathrm{x}} \mathrm{O}_{3-\alpha}$ showed those of the orthorhombic single phase which have been previously reported in the literature. ${ }^{3}$ The best catalytic ODH yield does correspond to the perovskite doped with $\mathrm{Ca} ; \mathrm{Ca}^{2+}(0.99 \AA)$ and $\mathrm{Ce}^{4+}$ $(0.92 \AA)$ are the closest in ionic radii as compared to the other dopant elements. However, with the series of $\mathrm{Ba}_{1-x} \mathrm{M}_{\mathrm{x}} \mathrm{CeO}_{1-\alpha}$ (where $\mathrm{X}=\mathrm{Mg}, \mathrm{Ca}$, Sr with $\mathrm{x}=0.2$ ), mixtures of the orthorhombic phase and of pure $\mathrm{CeO}_{2}$ were present on the XRD patterns. Examination of the ionic radii of the different elements in the metal oxide catalyst shows that while $\mathrm{Sr}^{2+}$ is close in size to barium (and easily substitutes into the perovskite site), $\mathrm{Ca}^{2+}$ and $\mathrm{Mg}^{2+}$ more closely match the cerium ion and selectively substitute into that octahedral site (forcing excess $\mathrm{CeO}_{2}$ to crystallize in addition to the perovskite).

The catalyst samples from figure 2 were characterized by XRD after recovery. $\mathrm{XRD}$ data shown in Figure 3 is exemplary of the $\mathrm{BaM}_{\mathrm{x}} \mathrm{Ce}_{1-\mathrm{x}} \mathrm{O}_{3-\alpha}$ series. The catalyst remains orthorhombic through $600^{\circ} \mathrm{C}$. However, at $700^{\circ} \mathrm{C}$, there is clearly a break down of the original perovskite phase; the resultant phases are a combination of $\mathrm{BaCO}_{3}$ and $\mathrm{CeO}_{2}$. The broadness of the XRD peaks can be due to decreased particle size or overlap of doped main phases (e.g., $\mathrm{Ba}_{\mathrm{x}} \mathrm{Ce}_{1-\mathrm{x}} \mathrm{O}_{2}$ ). 


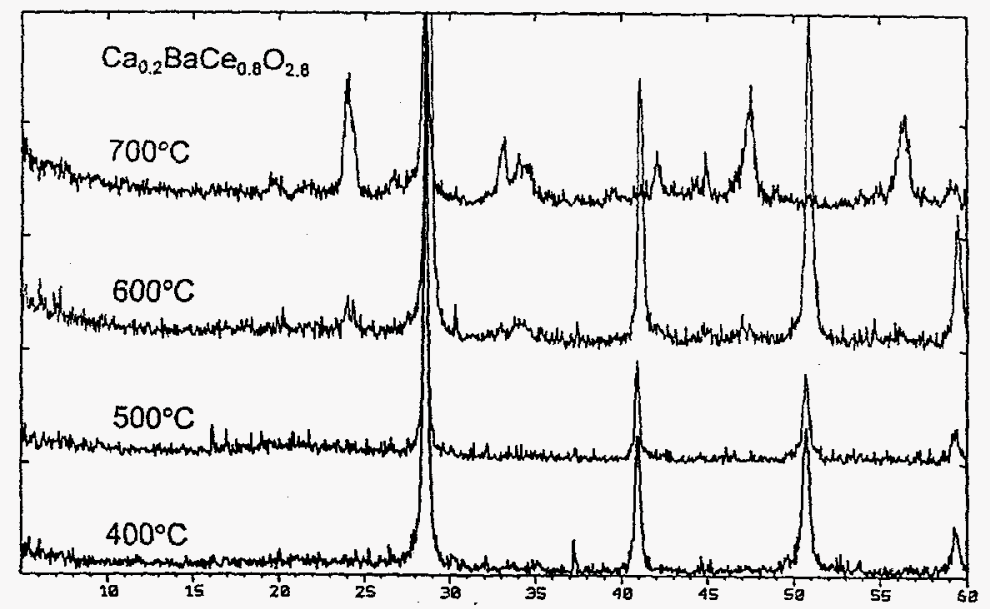

Figure 3: Powder $\mathrm{X}$-ray diffraction of $\mathrm{Ca}_{0.2} \mathrm{BaCe}_{0.8} \mathrm{O}_{2.8}$ with respect to temperature.

XPS: Initial XPS analysis of all of the perovskites reveals the expected presence of $\mathrm{Ba}$, $\mathrm{Ce}, \mathrm{C}$ and $\mathrm{O}$ on the surface of the catalyst, as well as $\mathrm{Mg}$ or $\mathrm{Ca}$ for perovskites containing these dopants. The $\mathrm{Ce} 3 \mathrm{~d} / \mathrm{Ba} 3 \mathrm{~d}_{5 / 2}$ intensity ratio, after correcting for relative sensitivity factors, ${ }^{18-20}$ corresponds to the expected $\mathrm{Ba} / \mathrm{Ce}$ atomic ratio of $\sim 1.0$ for all of the perovskites studied. Upon subjecting the perovskites to thermal treatments in various reactive environments, the $\mathrm{Ce} 3 \mathrm{~d} / \mathrm{Ba} 3 \mathrm{~d}_{5 / 2}$ ratio invariably declines with increasing severity of the treatment, ultimately approaching zero following treatment in ethane/ $\mathrm{CO}_{2}$ mixtures at $700^{\circ} \mathrm{C}$ (figure 4). At this stage, both the $\mathrm{C} 1 \mathrm{~s}$ and $\mathrm{O}$ 1s XPS regions reveal the presence of substantial amounts of carbonate, and very little metal oxide. Very little $\mathrm{CeO}_{2}$ surface is present relative to the $\mathrm{BaCO}_{3}$ surface, and the surface sensitive XPS technique detects mainly $\mathrm{Ba}$. The catalyst surface following reaction at $700^{\circ} \mathrm{C}$ clearly consists mainly of $\mathrm{BaCO}_{3}$.

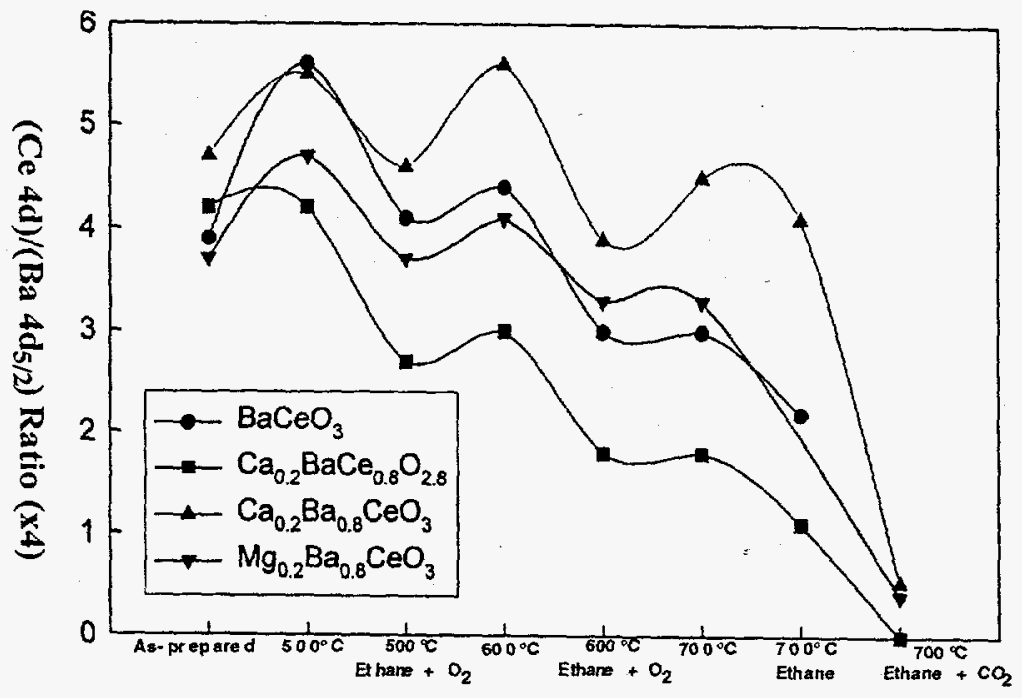

Figure 4: Decline of Ce (as monitored by XPS) on catalyst surface with temperature.

We focused on one of the better performers. The XPS analysis of the Ca containing perovskites indicates that both additives are initially present on the surface in 
amounts that are close to or slightly below the expected stoichiometric values. Upon subjecting the $\mathrm{Ca}$ containing materials to increasingly severe reaction conditions, the $\mathrm{Ca}$ $2 \mathrm{p}$ signal decreases relative to the $\mathrm{Ba} 3 \mathrm{~d}_{5 / 2}$ signal, ultimately falling to a value approximately one third that expected for a uniform stoichiometric mixture. During decomposition of the perovskite structure, the $\mathrm{Ca}$ becomes associated primarily with the $\mathrm{CeO}_{2}$ phase, which exposes very little surface area to the XPS probe. (Confirmed by XRD.)

Furthermore, it should be mentioned that the Ce $3 \mathrm{~d}$ peak shapes prior to any treatments do not correspond to fully oxidized $\mathrm{Ce}^{4+}$. Instead the spectra indicate a mixture of $\mathrm{Ce}^{3+}$ and $\mathrm{Ce}^{4+}$. Upon heating in vacuum, the extent of oxidation of $\mathrm{Ce}$ generally increases, indicating that diffusion of oxygen from the bulk to the surface is occurring. During treatment in reactive environments, the Ce becomes more highly reduced, especially for treatments involving lean ethane/oxygen mixture or pure ethane. Taken together these results are consistent with the expectation that these perovskite materials will allow efficient oxygen transport, and that $\mathrm{Ce}$ will undergo facile redox chemistry under reaction conditions. Both of these properties are essential to the proper functioning of oxidative dehydrogenation catalysts.

Literature ${ }^{14}$ reports have suggested that with the $\mathrm{ODH}$ catalyst $\mathrm{SrCe}_{1-\mathrm{x}} \mathrm{Yb}_{\mathrm{x}} \mathrm{O}_{3-0.5 \mathrm{x}}$, decomposition occurs above $700^{\circ} \mathrm{C}$, while conversion increases and selectivity decreases of the ethane. They show that $\mathrm{SrCO}_{3}$ and $\mathrm{Ce}_{1-\mathrm{x}} \mathrm{Yb}_{\mathrm{x}} \mathrm{O}_{2-0.5 \mathrm{x}}$ are formed. The result is explained as the Ce containing phase having a potentially higher oxygen defect concentration than the parent oxide, and is postulated to be reduced from the $4+$ to $3+$ oxidation state. Combining this information with our characterization data, we show that at $700^{\circ} \mathrm{C}$, there is a great amount of oxygen availability in the catalyst. XPS shows a changing in the oxidation state of the cerium from $4+$ to $3+$, which eventually leads to a collapse of the perovskite-like structure and resulting in a carbonate and oxide (with variability as to the location of the dopant in the structure). Furthermore, our catalyst testing shows that there is an enhanced activity and selectivity of our alkali metal doped catalysts at $700^{\circ} \mathrm{C}$ in the initial moments of the reaction for granules and for longer periods with powders. One explanation is that just as the perovskite-like phase is collapsing we have a very active and selective catalyst for the ODH of ethane. Our intent is to isolate the most active phase and further study its structure property relationships during catalysis.

\section{CONCLUSIONS}

In our catalytic studies of doped $\mathrm{Ba} / \mathrm{Ce} / \mathrm{O}$ perovskite-like metal oxides, the structure of the catalyst is lost before $700^{\circ} \mathrm{C}$. In-depth characterization of the catalyst by XPS has found that the majority of the working catalytic surface area consists primarily of $\mathrm{BaCO}_{3}$. However, further study is needed to understand if this is due to particle size effects or actual atom migration during reactions. The XPS studies also confirm literature XRD accountings ${ }^{14}$ of cerium oxidation state changes during the ODH of ethane in similar materials. 
Future work will focus on more fully understanding the effects of dopant elements (oxidation states and atomic radii) on these $\mathrm{Ba} / \mathrm{Ce} / \mathrm{O}$ perovskite-like metal oxides materials. Specifically, we will focus on synthetically mapping the composition range and substitution effects for the alkaline earth metals as dopants, and characterizing with XPS, TEM, GC and quantitative XRD analyses of the catalysts and the resultant metal oxide phases.

\section{ACKNOWLEDGMENTS}

This work was supported by the United States Department of Energy under contract DE-AC04-94AL85000. Sandia is a multiprogram laboratory operated by Sandia Corporation, a Lockheed Martin Company, for the United States Department of Energy.

\section{REFERENCES}

1. E. S. Linpinsky, J. D. Ingham, Brief Characterization of the Top 50 US Commodity Chemicals, USDOE, ILA 207376-A-H1, Sept. 1994. Also see: Chemical \& Engineering News, April 8, 1996, p. 17.

2. J. A. Labinger, K. C. Ott, S. Metha, H. K Rockstad, S. Zoumalan. J. Chem. Soc., Chem. Comm., p. 543 (1987).

14. S.R. Vatcha, Catalytica, Studies Division: Oxidative Dehyrogenation and Alternative Dehydrogenation Processes, Study Number 4192 OD, 1993.

15. E. M. Thorsteinson, T. P. Wilson, F. G. Young, P. H. Kasai, J. Catal. 52, p. 116 (1978).

3. R. A. Bayerlein, A. J. Jacobson, K. R. Poeppelmeyer, US 4,482,644, 1984.

4. R. A. Bayerlein, A. J. Jacobson, K. R. Poeppelmeyer, US 4,503,166, 1985.

5. R. A. Bayerlein, A. J. Jacobson, K. R. Poeppelmeyer, J. Chem. Soc., Chem. Commun., p. 225 (1988).

6. R. J. H. Verhoeve, Advanced Materials in Catalysis; Burton, J. J.; Garten, R. L., Eds.; Academic: New York, 1977, p. 129.

7. H. Iwahara, T. Esaka, H. Uchida, N. Maeda, Solid State Ionics, 3/4, p. 359 (1981).

8. T. Yajima, H. Iwahara, Solid State Ionics, 50, p. 281 (1992).

9. H. Iwahara, H. Uchida, K. Ono, K. Ogaki, J. Electrochem. Soc. 135(2), p. 529 (1988).

10. M. K. Paria, H. S. Maiti, Solid State Ionics. 13, p. 285 (1984).

11. D. Mastromonaco, 1. Barbariol, A. Cocco, Ann. Chim. (Rome). 59, p. 465 (1969).

12. O. J. Velle, A. Andersen, K.-J. Jens, Catalysis Today. 6, p. 567 (1990).

13. G. Yi, T. Hayakawa, A. G. Andersen, K. Suzuki, S. Hamakawa, A. P. E. York, M. Shimizu, K. Takehira, Catalysis Letters. 38, p. 189 (1996).

16. A. G. Sault, E. P. Boespflug, C. H. F. Peden, J. Phys. Chem. 98, 1652 (1994).

17. A. G. Sault, J. Catal. 156, 154 (1995).

18. C. D. Wagner, H. A Six, W. T. Jansen, J. A. Taylor, Appl. Surface Sci. 9, 203 (1981). 19. C. D. Wagner, W. M. Riggs, L. E. Davis, J. F. Moulder, G. E. Muilenberg, Handbook of X-ray Photoelectron Spectroscopy. Perkin-Elmer Corp., Eden Prairie, MN, 1979. 20. C. D. Wagner, L. E. Davis, M. V. Zeller, J. A. Taylor, R. H. Raymond, L. H. Gale, Surface Int. Anal. 3, 211 (1981). 